\title{
Damage evolution analysis of rock under Uniaxial compression and Brazilian splitting based on discrete element method
}

\author{
Li De-kang ${ }^{1,2 *}$, Li Hao-ran ${ }^{1,2}$, Liu Meng ${ }^{3}$, Wang Zi-heng ${ }^{1}$, Li Zheng ${ }^{1}$ \\ ${ }^{1}$ Structural Health Monitoring and Control Institute, Shijiazhuang Tiedao University, Shijiazhuang, Hebei, 050043, China \\ ${ }^{2}$ The Key Laboratory for Health Monitoring and Control of Large Structures, Shijiazhuang Tiedao University, Shijiazhuang, Hebei, \\ 050043, China \\ ${ }^{3}$ The second geological team of Hebei Coalfield Geological Bureau, Xingtai, Hebei, 054001, China
}

\begin{abstract}
In order to better analyze the mechanical behavior of rock in uniaxial compression and Brazilian splitting, numerical model was established according to laboratory test by $\mathrm{PFC}^{2 \mathrm{D}}$ particle flow program, and the simulation results were compared with the experimental results. The results show that when the rock reaches the peak stress, the failure curve of cement appears an obvious turning point, and the failure rate of cement increases. The compressive strength of rock is much greater than the tensile strength under compression condition. The preloading method is more detailed for experimental restoration, and it provides certain reference significance for rock simulation in the future.
\end{abstract}

\section{Introduction}

Rock is a kind of brittle material with natural nonuniformity. It is composed of tiny mineral particles bonded to each other and contains many tiny joints and fissures. With the development of computer technology, only studying the macroscopic mechanical properties of rock is not enough to solve the existing problems in rock engineering. In addition, uniaxial compression and Brazilian splitting are the most basic and important test methods used to test the compressive strength and tensile strength of rocks in rock mechanics tests. Moreover, traditional mechanical tests have disadvantages such as high cost and non-repeatability of rock samples. Therefore, in this paper, a numerical model of uniaxial compression and Brazilian cleavage was established to explore the mechanism of meso damage evolution in rocks from the macro and meso perspectives. Starting from the basic understands the correlation characteristics of rock mass, and provides important theoretical significance and engineering value for the future rock mass engineering stability analysis.

In order to understand the mechanism of rock fracture, many scholars have done a lot of laboratory tests and numerical simulation studies. In terms of laboratory tests, Wang Jun et al. ${ }^{[1]}$ carried out uniaxial compression tests of concrete with different carbonization degrees, recorded acoustic emission signals during concrete fracture process, and deeply explored the influence of carbonization on concrete mesoscopic failure mechanism. Yang Erhao ${ }^{[2]}$ carried out experiments on uniaxial compression mechanical properties, acoustic emission properties and fracture evolution law of different types of coal-rock complexes to explore mechanical change characteristics and damage evolution law of different types of coal-rock complexes. Hu Mingming et al. ${ }^{[3]}$ carried out uniaxial compression tests on sandstone, and conducted acoustic wave tests in three directions simultaneously during the loading process to explore the evolution law of acoustic wave velocity and stress in three different directions during the loading process of sandstone. Chen Zhajun et al. ${ }^{[3]}$ conducted Brazilian splitting and conventional uniaxial compression tests on sand slate, sandstone and mudstone to explore the mechanical properties and failure correlation characteristics of these three kinds of rocks. In terms of numerical simulation, Li Yong et al. ${ }^{[4]}$ based on the discrete element theory, studied the crack initiation, propagation, lashing and transfixion mechanism of cement mortar specimens containing parallel double cracks under different crack dip angles and uniaxial compression, and analyzed the evolution law of crack propagation from the perspective of stress field and displacement field. Shen Haimeng et al. ${ }^{[5]}$ conducted uniaxial compression test using $\mathrm{PFC}^{2 \mathrm{D}}$ particle flow program to explore the brittle failure process of salt rocks under different stress conditions. Dong Zhikai et al. ${ }^{[6]}$ used particle flow program $\mathrm{PFC}^{2 \mathrm{D}}$ to simulate uniaxial compression test of Dali rocks, and explored the evolution law of mesoscopic damage in rocks.

Uniaxial compression and Brazilian splitting are the most basic test methods to study the mechanical characteristics of rocks, In this paper, the numerical simulation of uniaxial compression and Uniaxial compression was carried out respectively to explore the damage evolution law of rock fracture in the process of uniaxial compression from a microscopic perspective, and analyzed the correlation characteristics between Brazilian 
splitting and uniaxial compression.

\section{Numerical modeling and parameter calibration}

\subsection{The establishment of numerical model}

In this paper, a two-dimensional uniaxial compression model is established on the basis of other experiments ${ }^{[7]}$. The model size was set as $\Phi 50 \mathrm{~mm} \times 100 \mathrm{~mm}$, the particle size range was $0.3 \mathrm{~mm} \sim 0.45 \mathrm{~mm}$, obeying uniform probability distribution, and a total of 10263 particles were generated. The upper and lower walls of the sample are used as loading plates for quasi-static loading of the sample, and the simulated loading speed is $0.01 \mathrm{~m} / \mathrm{s}$ (Quasistatic modeling usually uses high local damping coefficient to effectively remove the kinetic energy in the system, so typical quasi-static deformation is carried out at a much higher rate than the actual rate). The density and porosity of the rock sample were set at $2700 \mathrm{~kg} / \mathrm{m}^{3}$ and 0.08 respectively. The constitutive model of contact simulated material was used for the particles, and the parallel bonding model was selected as the contact model.

Uniaxial compression and Brazilian splitting are important bases for studying the physical and mechanical properties of rocks. This paper uses $\mathrm{PFC}^{2 \mathrm{D}}$ to establish a Brazilian split model (Fig.1), and single axial compression to explore the microscopic mechanical properties of the rocks. The size of the numerical model was $50 \mathrm{~mm}$ in diameter, and the particle size range was $0.3 \mathrm{~mm} \sim 0.45 \mathrm{~mm}$. A total of 4007 particles were generated.The density and porosity of the rock sample were set at $2700 \mathrm{~kg} / \mathrm{m}^{3}$ and 0.08 respectively. The rock sample adopted parallel contact model.

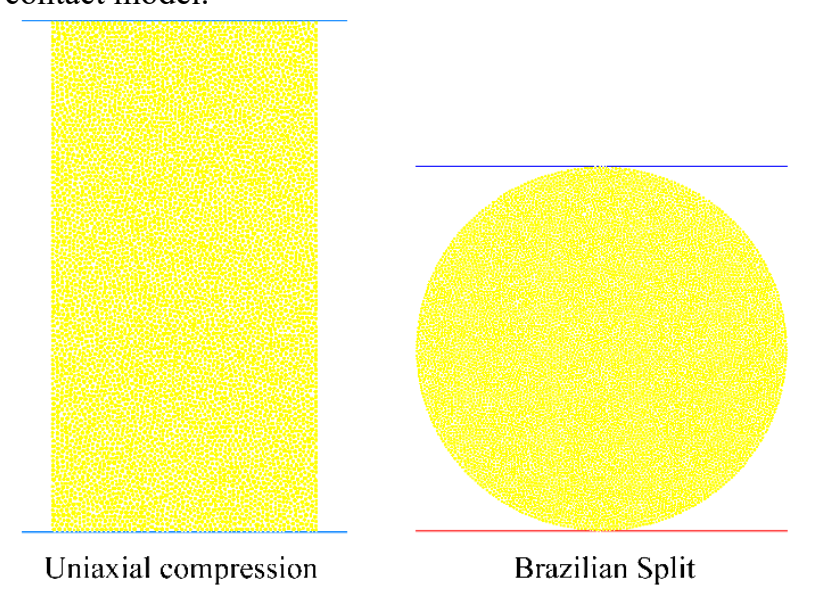

Fig. 1. Model of theUniaxial compression and Brazilian split

\subsection{The determination of constitutive contact model parameters}

In view of the complexity of rock mass meso structure and the limitation of research level, mature mechanical theory has not been formed to characterize the characteristic relationship of rock mass macro-meso parameters at present ${ }^{[8,9]}$. According to the existing literature, in the numerical simulation of rock mass, the elastic theory of granular particles indicates that the model has good convergence when the stiffness ratio is between $1 \sim 3$. The friction coefficient mainly affects the internal friction Angle of the rock, and the friction coefficient ranges from $0.2 \sim 0.6$. This paper combines the existing parameter ranges and determines a reasonable set of parameters through constant debugging and comparison (Table1). The uniaxial compression curve simulated by using the parameters in Table 1 is compared with the stress-strain curve tested (Table2 and Fig.2). The numerical simulation of stress-strain is basically consistent with the laboratory test, and the two have similar mechanical effects, which verifies the rationality of the parameters obtained in this paper.

Table 1 Microparameters of the numerical model

\begin{tabular}{|c|c|}
\hline Micro parameters & Numerical value \\
\hline Density $\left(\mathrm{kg} / \mathrm{m}^{3}\right)$ & 2700 \\
\hline $\begin{array}{c}\text { Coefficient of intergranular } \\
\text { friction }(u)\end{array}$ & 0.5 \\
\hline $\begin{array}{c}\text { Particle normal to tangential } \\
\text { stiffness ratio }\left(k_{\mathrm{n}} / k_{\mathrm{s}}\right)\end{array}$ & 1.5 \\
\hline $\begin{array}{c}\text { Modulus of elasticity of } \\
\text { particles }(\mathrm{Pa})\end{array}$ & $25 \mathrm{e} 9$ \\
\hline $\begin{array}{c}\text { Modulus of elasticity for } \\
\text { parallel bonding }(\mathrm{Pa})\end{array}$ & 1.5 \\
\hline $\begin{array}{c}\text { The stiffness ratio of normal to } \\
\text { tangential of parallel bonding } \\
\left(k_{\mathrm{n}} / k_{\mathrm{s}}\right)\end{array}$ & $120 \mathrm{e} 6$ \\
\hline $\begin{array}{c}\text { Normal bonding strength of } \\
\text { parallel bonding (Pa) }\end{array}$ & $40 \mathrm{e} 6$ \\
\hline $\begin{array}{c}\text { Tangential bonding strength } \\
\text { of parallel bonding (Pa) }\end{array}$ & \\
\hline
\end{tabular}

Table 2 Basic mechanical parameters of laboratory tests and numerical simulation of rock samples

\begin{tabular}{|c|c|c|c|}
\hline Type of experiment & $\begin{array}{c}\text { peak } \\
\text { strength }\end{array}$ & $\begin{array}{c}\text { elasticity } \\
\text { modulus }\end{array}$ & $\begin{array}{c}\text { Peak axial } \\
\text { strain }\end{array}$ \\
\hline Laboratory test & 106.0 & 32.5 & 0.00369 \\
\hline Numerical simulation & 104.1 & 33.6 & 0.00365 \\
\hline
\end{tabular}

\section{Analysis of numerical results}

\subsection{Stress-strain curve of rock}

Fig. 2 shows the stress-strain situation during rock loading and the bonding bond fracture ratio. It can be seen from Fig. 2 that in each stage of the rock's stress-strain curve obtained by numerical simulation, the cementation failure inside the rock shows the following characteristics as the strain changes.

(1) In the OA section, the rocks are in the compaction process, and the bonding bonds between particles in the sample model are almost not broken.

(2) In the $A B$ section, the cementation failure inside the rock began to be active and gradually increased, and the cementation failure point began to expand and form microcracks.

(3) In the BC section, point B is the peak stress point of the rock. It can be seen from the cementing failure curve of the sample model that when the rock reaches the peak stress, the cementing failure curve appears an obvious turning point and the cementing failure rate increases. 


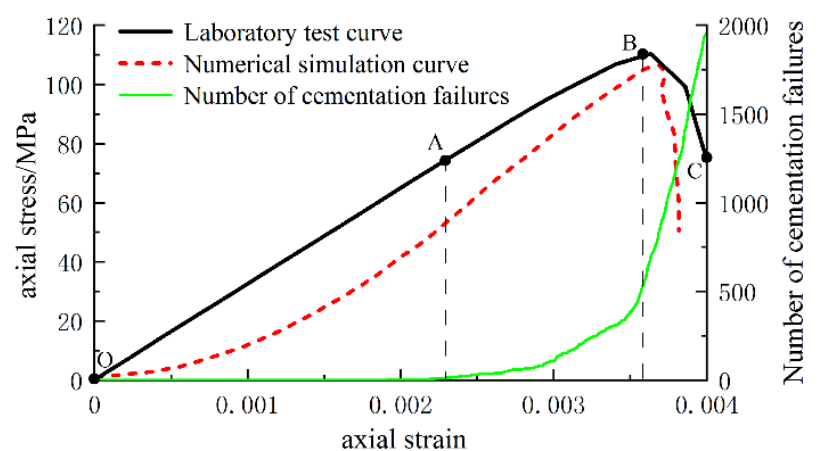

Fig. 2. Comparison of stress-strain curves and cementing failure curves of rock

\subsection{Relationship between Uniaxial compression and Brazilian cleavage}

In this paper, the Brazilian splitting model is established by using the same set of parameters, and the tensile strength and elastic modulus of the model are obtained by numerical simulation, respectively $10.4 \mathrm{MPa}$ and $1.13 \mathrm{GPa}$. The ratio of the compressive strength of uniaxial compression to the tensile strength obtained by Brazilian splitting is 10 , and the ratio of the elastic modulus of uniaxial compression to the elastic model of Brazilian splitting is 29.73. It can be seen that the compressive strength of the rock under compression is much greater than the tensile strength, which is consistent with some conclusions $^{[10]}$ and also verifies the accuracy of the model in this paper.

\section{Discussion}

In order to make the numerical model more detailed, a new numerical simulation sequence is established in this paper. The uniaxial compression of real rock samples underwent four processes: particle deposition, particle cementation, rock removal and uniaxial loading. The uniaxial numerical model in this paper underwent precompression, cementation, unloading and uniaxial loading, and the two processes were corresponding to each other. Generally, rocks are affected by the dead weight stress underground, and the pre-compression in this paper is the dead weight stress given to the model, which is not only suitable for uniaxial compression, but also suitable for triaxial compression, slope, tunnel and so on. In this way, the real space of rocks will be more restored.

\section{Conclusion}

In this paper, uniaxial compression and Brazilian splitting models were established by using particle flow program $\mathrm{PFC}^{2 \mathrm{D}}$, and the following conclusions were obtained through macro and micro analysis.

(1) During uniaxial compression, after the rock reaches the peak stress, the cementing failure curve appears an obvious turning point, and the cementing failure rate increases.

(2) The ratio of the compressive strength of uniaxial compression to the tensile strength obtained by Brazilian splitting is 10 , and the ratio of the elastic modulus of uniaxial compression to the elastic model of Brazilian splitting is 29.73. The compressive strength of rocks under compression is much greater than the tensile strength.

(3) The preloading method adopted in this paper can restore the real space of the rock more and establish a more detailed model, which has certain practical significance for the study of the failure mechanism of the rock.

\section{Reference}

1. Wang Jun, Wei Yanqing, Ding Yao, et al. Acoustic Emission characteristics of carbonized concrete under uniaxial compression [J].Journal of Chengdu University of Technology (Natural Science), 2020, 47(04): 498-505.

2. Yang Er-hao. Experimental Study on uniaxial compression acoustic emission characteristics and Fracture expansion law of Coal and rock mass [D]: Xi 'an University of Science and Technology, 2019.

3. $\mathrm{Hu}$ Mingming, Zhou Hui, Zhang Yonghui, et al. Acoustic characteristics of sandstone during uniaxial loading [J].Rock and Soil Mechanics, 2018, 39(12): 4468-4474.

4. Li Yong, Cai Gongjun, Zhu Weishen, et al. Particle flow analysis of parallel double fractures under uniaxial compression [J].Journal of Central South University (Natural Science), 2019, 50(12): 30353045.

5. Shen Haimeng, Li Qi, Li Xiaying, et al. Laboratory experiment and Numerical Simulation study on brittle failure characteristics of shale under different stress conditions in Longmaxi Formation, South Sichuan [J].Rock and Soil Mechanics, 2018, 39(S2): 254-262.

6. Dong Zhikai, Li Haoran, Ouyang Zuo-lin, et al. Study on the spatiotemporal evolution characteristics of acoustic emission from Dali rocks under uniaxial load [J].Journal of Underground Space and Engineering, 2019, 15: 609-615.

7. Zhao Haijun. Discrete element Simulation analysis of rock uniaxial compression test [J]. Shanxi Architecture, 2018, 44(11): 72-73.

8. Zhou Jian, Jia Mincai. Civil Meso model Test and Numerical Simulation $[\mathrm{M}]$. Beijing: Science Press, 2008.

9. Shi Chong, Xu Weiya. Numerical Simulation techniques and Practice of granular flow [M]. Beijing China Building Industry Press, 2015.

10. Chen Zhaojun, Wang Lehua, Jin Jing, et al. Comparative Study on Brazilian splitting and uniaxial compression tests of three kinds of rocks [J].Hydroelectricity, 2015, 41(11): 34-38. 